九州大学学術情報リポジトリ

Kyushu University Institutional Repository

\title{
Spatiotemporal Investigation of Atmospheric Water Harvesting Potential Using Response Surface Methodology for Multan (Pakistan) and Fukuoka (Japan)
}

Bi lal, Muhammad

Department of Agricultural Engineering, Bahauddin Zakariya University

Sultan, Muhammad

Department of Agricultural Engineering, Bahauddin Zakariya University

Miyazaki, Takahiko

Faculty of Engineering Sciences, Kyushu University

https://doi.org/10.5109/4102477

出版情報: Proceedings of International Exchange and Innovation Conference on Engineering \& Sciences (IEICES). 6, pp. 128-133, 2020-10-22. Interdisciplinary Graduate School of Engineering Sciences, Kyushu University バージョン：

権利関係 : 


\title{
Spatiotemporal Investigation of Atmospheric Water Harvesting Potential Using Response Surface Methodology for Multan (Pakistan) and Fukuoka (Japan)
}

\author{
Muhammad Bilal ${ }^{1}$, Muhammad Sultan ${ }^{1, *}$, Takahiko Miyazaki $^{2}$ \\ ${ }^{1}$ Department of Agricultural Engineering, Bahauddin Zakariya University, Multan 60800, Pakistan \\ ${ }^{2}$ Faculty of Engineering Sciences, Kyushu University, Kasuga-koen 6-1, Kasuga-shi, Fukuoka 816-8580, Japan. \\ Corresponding author email: muhammadsultan@bzu.edu.pk
}

\begin{abstract}
The concept of response surface methodology is to develop an explicit relationship between continuous and response variables through the regression and ANOVA analysis. In this study, the regression relationships were developed between the dry bulb temperature, relative humidity and atmospheric pressure as continuous variables and precipitable water as a response variable to check the variability of atmospheric water harvesting potential. The regression equations developed with the combinations of continuous variables for Multan (Pakistan) and Fukuoka (Japan) were also modified by analyzing the p-value. Only those combinations of continuous variables were selected which have p-value less than 0.05 because any change in these continuous variables affects the changes in response variable. The contour and residual plots were also developed for the analysis of model variation. These plots represent the range of maximum and minimum output of response variable. The response surface optimization was also analyzed to check the model accuracy.
\end{abstract}

Keywords: atmospheric water harvesting, response surface methodology, optimization, Pakistan, Japan

\section{INTRODUCTION}

Water is the basic need of humans as well as nonhumans. Humans use it for several purposes including personal hygiene and industrial use. The water scarcity is growing day by day and this condition is projected to increase to more than $66 \%$ of the world's population by 2025 because of high population growth rates and modern development in infrastructure [1]. To overcome this problem, the atmospheric water harvesting (AWH) is one of the solutions that should be taken into consideration. AWH can be possible through many technologies i.e. fog water harvesting, dew condensation and vapor compression based atmospheric water harvesting [2-8]. For that purpose, first the atmospheric water harvesting potential areas must be identified and selected. Response surface methodology (RSM) is a group of mathematical and statistical techniques used to develop an adequate relationship between the continuous factors and the response factors[9-13]. Precipitable water is actually the depth of water that is collected in a column of atmosphere in millimeters. The collection of water can be done through the adsorption of water from atmosphere using desiccants [14,14-21]. The RSM is selected in this paper to analyze and optimize the water harvesting potential of Multan (Pakistan) and Fukuoka (Japan) by considering the dry bulb temperature (DBT), relative humidity (RH) and atmospheric pressure (ATM) as continuous factors and precipitable water $(\mathrm{Pw})$ as a response factor. The weather data is collected from the http://climate.onebuilding.org/. The detailed RSM methodology used in this paper is explained in the next section.

\section{RESPONSE SURFACE METHODOLOGY}

Response surface methodology is a set of statistical and mathematical techniques used in the empirical studies of relationships for improving and optimizing processes [22-26]. This methodology mostly used in three different methods/techniques (i) Optimization techniques/methods (ii) regression modeling techniques and (iii) two level factorial or fractional factorial statistical experimental technique [27-31]. The RSM extensive applications used in those situations where input parameters affected the quality characteristic of the whole process [25,32-34]. In this case, the quality characteristics are called response variables and the input variables are called the independent or continuous variables. These are the designs that working with continuous variables to find out the goal for response variable. Most RSM applications are sequential in nature. The graphical understanding of response surface is shown in Fig. 1. Each value of natural variables $x_{1}$ and $\mathrm{x}_{2}$ represents and generates the $\mathrm{y}$-values. The contour lines of $x_{1}$ and $x_{2}$ pairs shows the same response $y$-value. The RSM field first includes experimental strategy for the independent variables, then empirical modeling to develop a relationship between the continuous and the response variables and then optimize

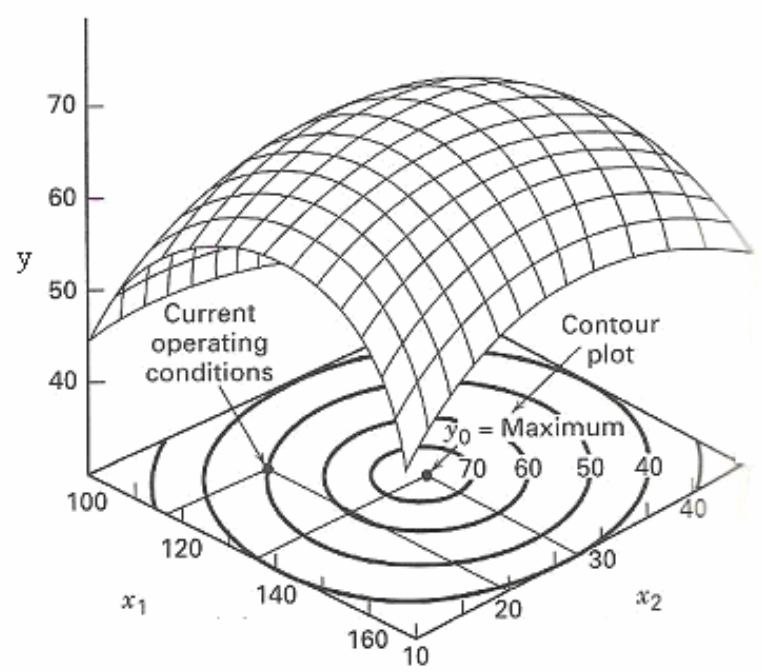

Fig. 1. Graphical representation of response surface plot with contour lines [35] 
the response surface modeling to find out the values for process or continuous variables that produces the most suitable and desirable values for the response factor. Statistical modeling to develop an appropriate model between the input variables $\left(\mathrm{x}_{1}, \mathrm{x}_{2}, \mathrm{x}_{3} \ldots\right)$ and response variable $(\mathrm{y})$, the general relationship is

$$
y=f(x 1, x 2, x 3, \ldots \ldots)+e
$$

where, the true response function $f$ is unknown and e represents the other uncertainties which are not accounted in $f$. These input variables $\left(\mathrm{x}_{1}, \mathrm{x}_{2}, \mathrm{x}_{3} \ldots\right)$ are also called the natural variables. The RSM includes some relationships for optimizing the response variable described in eq (2-6) which are presented in literature [27]

$E(y)=\eta=E[f(x 1, x 2, x 3, \ldots, x k)]+E(e)=$ $f(x 1, x 2, x 2, \ldots x k)$

$\xi_{i}=\frac{x_{i}-\left[\max \left(x_{i}\right)+\min \left(x_{i}\right)\right] / 2}{\left[\max \left(x_{i}\right)-\min \left(x_{i}\right)\right] / 2}$

$R^{2}=\frac{\sum_{i=1}^{n}\left(\hat{y}_{i}-\bar{y}\right)^{2}}{\sum_{i=1}^{n}\left(y_{i}-\bar{y}\right)^{2}}$

$R^{2}{ }_{a d j}=1-\frac{k-1}{k-p}\left(1-R^{2}\right)$

$\eta=\beta_{0}+\beta_{1} x_{1}+\beta_{2} x_{2}+\beta_{k} x_{k}$

$\eta=\beta_{0}+\sum_{j=1}^{k} \beta_{j} x_{j}+\sum_{j=1}^{k} \beta_{j j} x_{j}^{2}$

where, $\mathrm{x}_{1}, \mathrm{x}_{2}, \mathrm{x}_{3}$ represents the natural variables, max and min values covers the range of input variables, $\overline{\mathrm{y}}, \ddot{\mathrm{y}}_{i}$ and $y_{i}$ represents estimated mean value, actual value and predicted values of response (y)respectively. Eq (6) and (7) represents the general first-order and second-order model equations respectively.

\subsection{Central composite design}

Central composite design (CCD) is an experimental design used in response surface methodology to build a second order model for a response. It has advantages over other design is that it allows the designer to analyze the relationship and to know how factors effects the response variable. It includes three distinct sets of experimental runs which are factorial design, a set of center points and a set of axial points. This design consists of a complete $2 \mathrm{k}$ factorial design with an axial portion consists of $2 \mathrm{k}$ points. These $2 \mathrm{k}$ points can be selected on axis at a distance of $\alpha$ from the center of the design and also n0 center points. Fig. 2. shows the scheme of central composite design with cubic, star and center points. The CCD provides high quality predictions for developing linear and quadratic relationships of continuous and response factors. The number of experimental runs which can be obtained at each level and at each factor is given by the formula

$N=2^{n}+2 x n=n c$

where, $\mathrm{N}, \mathrm{n}$ and $\mathrm{nc}$ represents the number of runs, number of factors and the number of center points respectively. The value of $\alpha$ is necessary to get the axial points and can be calculated using $\alpha=2^{k / 4}$

where, $\mathrm{k}$ is the number of factors. The central composite design is selected in response surface methodology to analyze the potential of Atmospheric water harvesting by considering the weather data parameters (dry bulb temperature, relative humidity, atmospheric pressure) as the continuous parameters and the precipitable water in $\mathrm{mm}$ is considered as a response variable. The detailed discussion of results is explained in next section

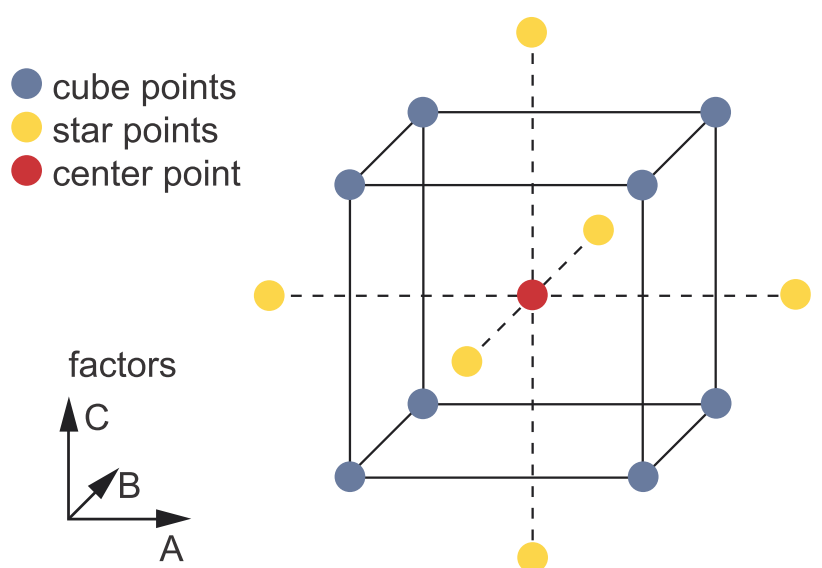

Fig. 2. Scheme of central composite design with cubic, star and center points [35].

\section{RESULTS AND DISCUSSION}

The atmospheric water harvesting potential is analyzed by the selection of suitable weather parameters for cities Multan (PK) and Fukuoka (JPN). The response surface methodology is based on the specific combinations for the number of factors to be tested and the number of levels for each of the factor. In this study, the combinations for the continuous variables (dry bulb temperature, relative humidity, atmospheric pressure) were checked against the response variable (precipitable water). The regression relationships were developed for each of the case study. The eq 10 and 11 represents the regression relationship between the continuous and response variable for Multan and Fukuoka cities respectively.

$$
\begin{aligned}
& P w(\text { Multan })=5200-17.82 D B T-10.302 R H- \\
& 0.095 A T M+0.193 D B T \times D B T+0.007977 R H \times \\
& R H+0.134 D B T \times R H
\end{aligned}
$$

$$
\begin{aligned}
& P w(\text { Fukuoka })=-2838-3.40 D B T-0.923 R H+ \\
& 0.0557 A T M+0.129 D B T \times D B T+0.0027 R H \times \\
& R H+0.067 D B T \times R H
\end{aligned}
$$

These equations are modified by analyzing the p-value. $\mathrm{P}$-value is the probability of finding results at least as extreme as the actual results observed. The continuous variables that has the $\mathrm{p}$-values $<0.05$ considered to be a meaningful addition to the model, because any change in the continuous variable is related to the change in the response variable. Conversely, larger p-values suggested that changes in continuous variables are not associated with the changes in the response variable. 


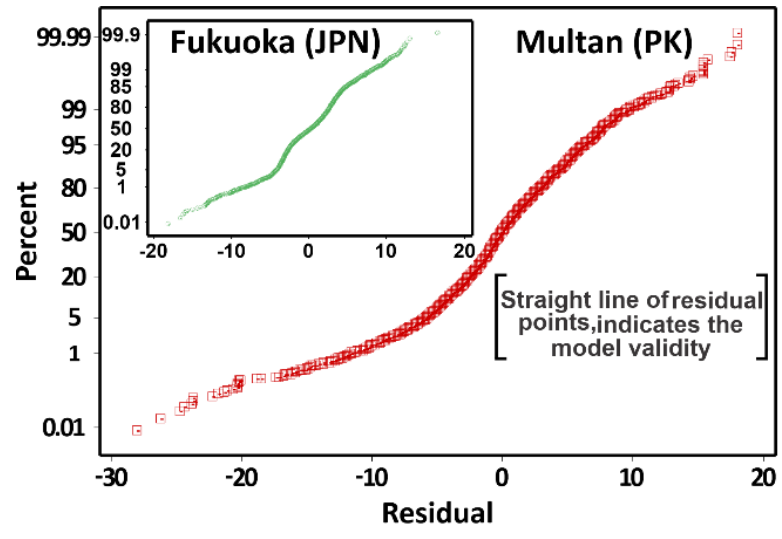

Fig. 3. Normal probability plot for Multan (PK) and Fukuoka (JPN)

Fig. 3. shows the residual plotting to examine the goodness of response surface model in regression and as well as in analysis of variance (ANOVA). This plotting helps us to understand and to determine whether the ordinary least squares assumptions are being satisfied. If these ordinary least squares assumptions are met, then it will produce unbiased coefficients with the least variance. It represents the normal probability plot between the residuals and percent. Generally, the points in this plot makes a straight line because of the residuals are normally distributed. If the points are not generating a straight line then model is invalid. The model can also be validated using the relationship between the residuals and fitted values. This plotting generally shows a random pattern of residuals on both sides of 0 . All the points should be in a same manner and if any point lies far from the majority of points, then it may be called an outlier. But the residual points should not be recognized with any pattern. For instance, if the majority of residual values increases as the fitted values of the model increases, then we can say that it violates the constant variance assumption. The histogram variation of the residuals is also indicating the model fitness. This explains the general characteristics of the residuals that includes the shape, spread and values for each of the residual. A skewed distribution can be analyzed through the histogram plotting and also if one or two bars are not in line with each other and far from the others, then those points may be called as outliers. Other than normal probability plotting the variation between the residuals and the observation order is also significant for model. validation. Basically, this plotting shows all residuals in an order for which the data was collected and can be analyzed and used to determine the non-random errors. The time-related effects can also be finding out with this kind of plot variation. This plotting also helps to check and optimize the assumption whether the residuals are uncorrelated with each other or not. The assumptions are also analyzed with this plotting. The residuals can also be drawn versus predictors to analyze the random pattern on both sides of 0 . The contour plots are also developed for establishing the desirable values and conditions for process completion. Contour plot is actually a projection of 3D graph on a 2D plot, it represents the maximum and minimum areas and as well as the effect of continuous variables on the certain response variables. It helps to understand a relationship between the two factors on the response. Fig. 4. shows the contour plotting for Multan (Pakistan) and Fukuoka (Japan) between the two continuous variables (dry bulb temperature and relative humidity) to check and optimize the effect of these variables against the response variable (precipitable water). It can be observed that a high amount of precipitable water is obtained at high temperature and relative humidity. Most of the contour region lies in between from 0-100 $\mathrm{mm}$ precipitable water for Multan and $0-50$ for Fukuoka. The darker regions (green) identify higher precipitable water $(\mathrm{mm})$. A significant difference in potential of atmospheric water harvesting is noted in both cities. Fig. 5. shows the contour plotting for a Multan (Pakistan) and Fukuoka (Japan) city between the dry bulb temperature and atmospheric pressure against the precipitable water. This plotting represents how both continuous variables are responsible for a change in response variable. This kind of variation represents that most of the precipitable water which can harvested is in between $<50 \mathrm{~mm}$ for Multan and $<20 \mathrm{~mm}$ for Fukuoka. From this it can be seen that there is no significant impact of combination of these two continuous variables on a response variable. At $45^{\circ} \mathrm{C}$ dry bulb temperature and $101000(\mathrm{~Pa})$ atmospheric pressure, the maximum precipitable water is available for harvesting in Multan. While, at above $35^{\circ} \mathrm{C}$ dry bulb temperature and $100000(\mathrm{~Pa})$ atmospheric pressure, the maximum precipitable water can be harvested. Fig. 6 represents the response surface optimization analysis

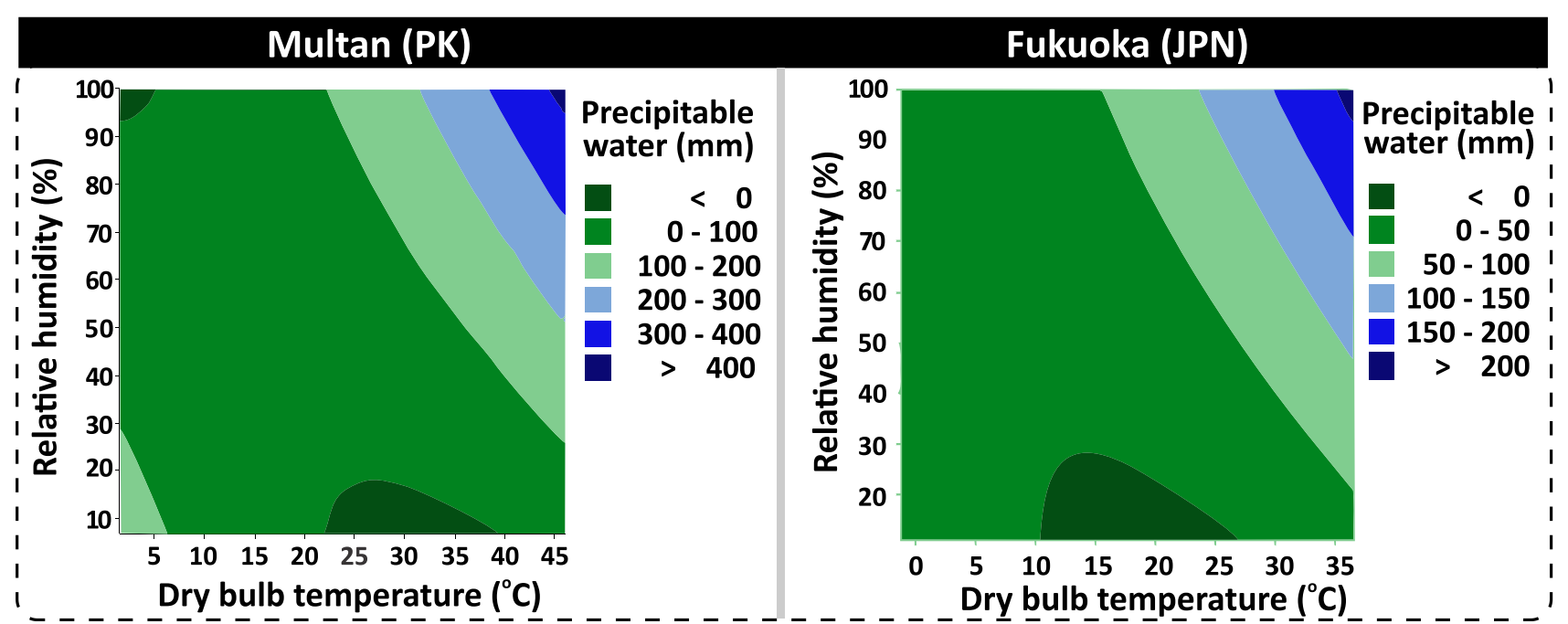

Fig. 4. Contour plots variation between dry bulb temperature and relative humidity against the precipitable water 


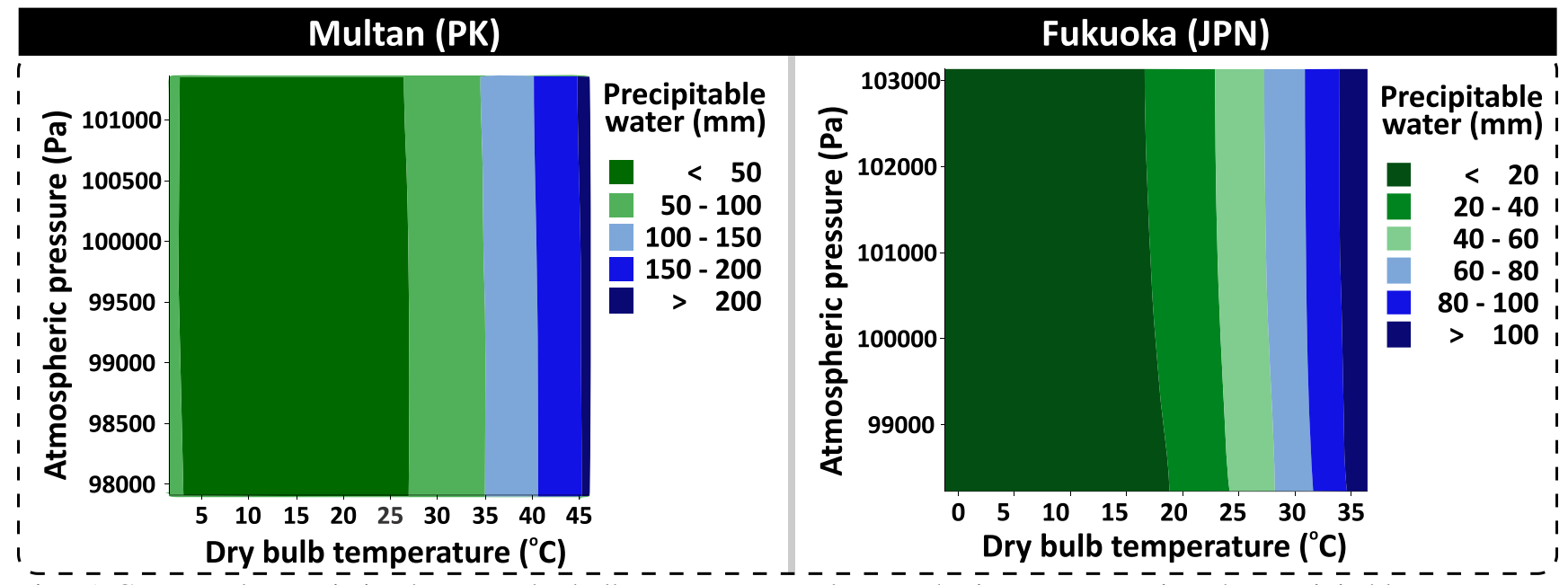

Fig. 5. Contour plots variation between dry bulb temperature and atmospheric pressure against the precipitable water

for Fukuoka (Japan). The multi-response optimization analysis helps to find out the operating conditions and desirable functions on the input or continuous variables that finds the optimal or near optimal response values for a response function. It shows the maximum output of precipitable water of $216.1859 \mathrm{~mm}$ at $36.50^{\circ} \mathrm{C}$ dry bulb temperature, $100 \%$ relative humidity and 102470.091 Pa atmospheric pressure. While, for Multan (Pakistan), the maximum output of precipitable water which can be collected is $427.4873 \mathrm{~mm}$ at $46{ }^{\circ} \mathrm{C}$ dry bulb temperature, $100 \%$ relative humidity and 99620.3057 atmospheric pressure. Table 1. describes the optimized values of precipitable water for selected cities. Fig. 7. represents the maximum and average precipitable water for some of the cities of Pakistan and Japan. It can be seen that from the illustration that the maximum amount of water which can harvested from Multan, Lahore, Faisalabad, and Karachi is 160, 169 and $172 \mathrm{~mm}$ respectively. While for Fukuoka, Osaka, Tokyo, Yokohama is 136, 118, 128 and 128 respectively. And the average amount of water for Fukuoka, Osaka, Tokyo and Yokohama lies in between $0-45 \mathrm{~mm}$. This represents the moderate potential of atmospheric water harvesting for these cities. The average amount of precipitable water which can be collected form Multan, Lahore, Faisalabad and Karachi lies in between 45-90mm which represents a high potential for atmospheric water harvesting. Form the above perspective, it can be concluded that, the selected citied of Japan and Pakistan represents a moderate and high potential for atmospheric water harvesting respectively. The response surface methodology can be applied to other areas of world to identify the potential for AWH.

Table 1. Optimized precipitable water values for some of the cities of Pakistan and Japan

\begin{tabular}{ccc}
\hline \hline Sr \# & Cities & $\begin{array}{c}\text { Optimized values } \\
(\mathrm{mm})\end{array}$ \\
\hline 1 & Multan (PK) & 427.4873 \\
2 & Lahore (PK) & 380.4906 \\
3 & Fukuoka & 216.1859 \\
& $(\mathrm{JPN})$ & 209.7182 \\
4 & Osaka (JPN) & \\
\hline \hline
\end{tabular}

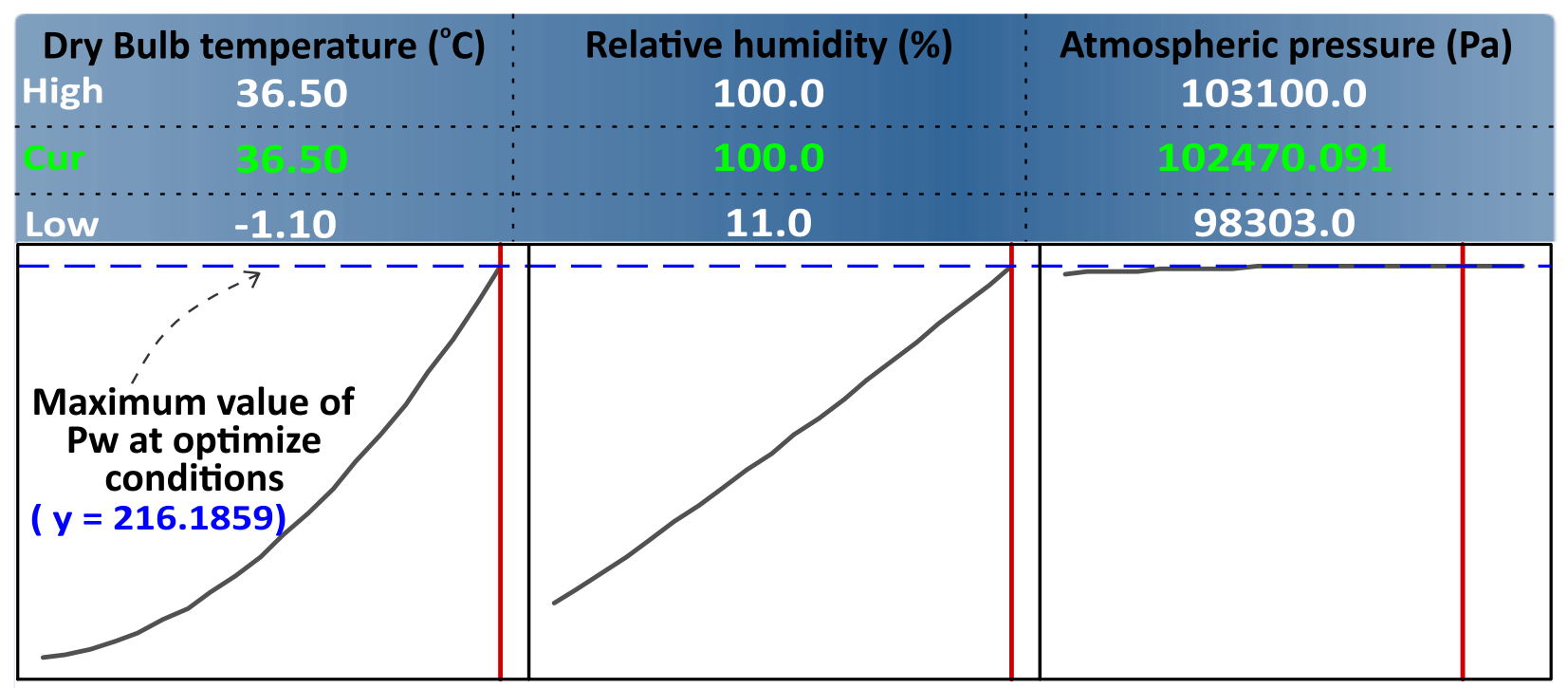

Fig. 6. Response surface optimization to achieve maximum output of precipitable water for Fukuoka (Japan) 


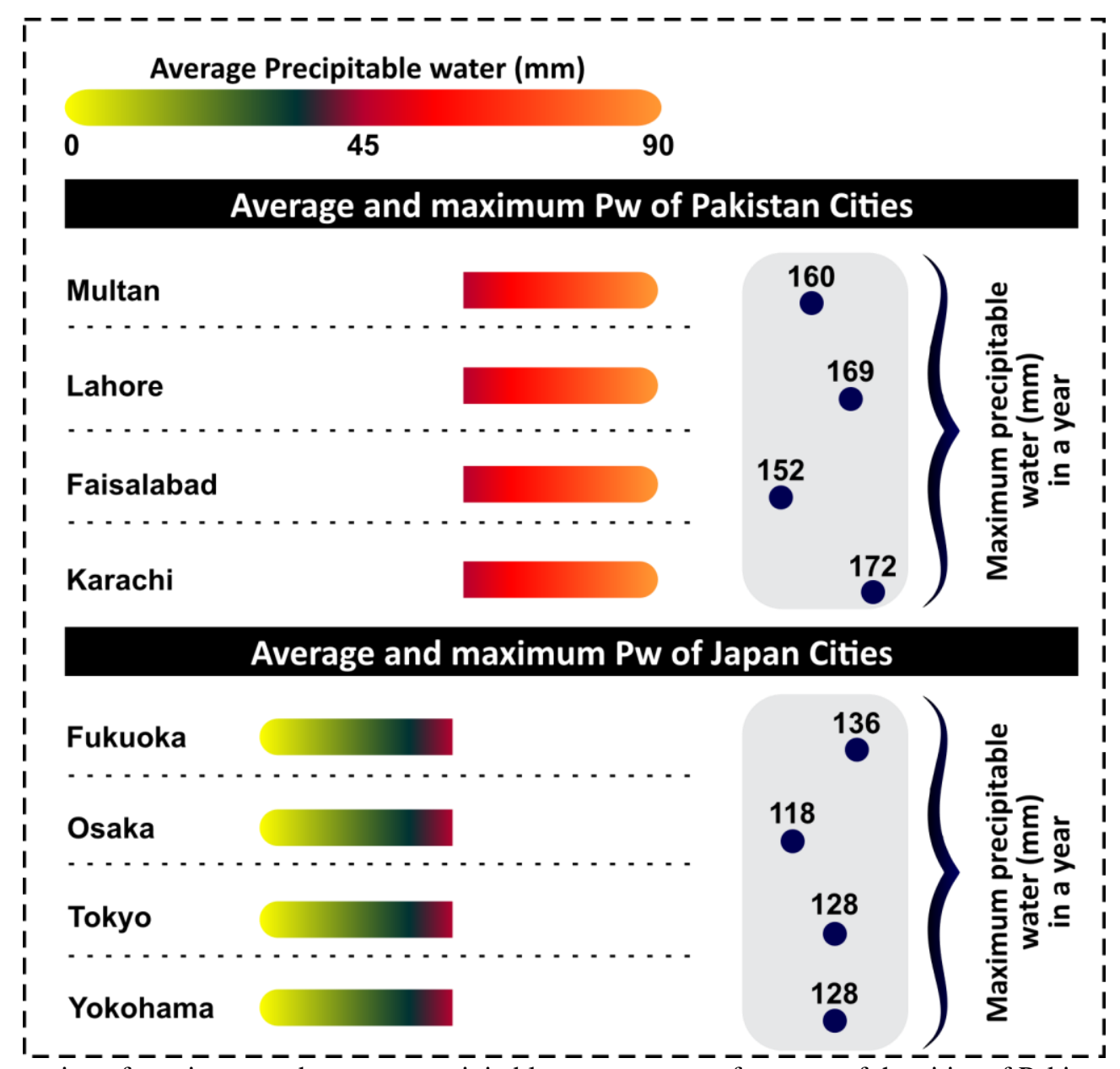

Fig. 7. Illustration of maximum and average precipitable water per year for some of the cities of Pakistan and Japan

\section{CONCLUSIONS}

Response surface methodology is used to develop relationships between predictor and response variables. This study includes the development of regression relationships between the dry bulb temperature, relative humidity and atmospheric pressure as the continuous variables and precipitable water as the response variable for the potential of atmospheric water harvesting. Cities of Pakistan and Japan were taken into consideration for the response surface modeling. Contour, residual and optimize plotting were developed for analysis. Optimization of response surface methodology was analyzed to check the goodness fit of model to the case studies (Multan, Fukuoka). From the analysis, it is concluded that Multan shows the average precipitable water amount in the range of $45-90 \mathrm{~mm}$. While, the Fukuoka city has the potential of $0-45 \mathrm{~mm}$. From that

\section{REFERENCES}

[1] Beysens D. 2018 Dew water. River Publishers; .

[2] Yang, SuKim H, Rao SR, Narayanan S, Kapustin EA, Furukawa H, Umans AS, et al. 2017 Powered By Natural Sunlight. Science (80- ) 434:430-4. https://doi.org/10.1126/science.aam8743.

[3] LaPotin A, Kim H, Rao SR, Wang EN. 2019 Adsorption-Based Atmospheric Water Harvesting: Impact of Material and Component Properties on System-Level Performance. Acc Chem Res 52:1588-97.

https://doi.org/10.1021/acs.accounts.9b00062. perspective, response surface modeling must be applied to identify the potential areas for atmospheric water harvesting

\section{Acknowledgements}

This research work has been carried out in the Department of Agricultural Engineering, Bahauddin Zakariya University, Multan-Pakistan. This research was funded by Bahauddin Zakariya University, MultanPakistan under the Director Research/ ORIC grant titled "Thermodynamic Evaluation of Low-Cost AirConditioning Systems for Various Applications" awarded to Principal Investigator: Dr. Muhammad Sultan.

\section{Conflict of interest}

The authors declare no conflict of interest.

[4] Ejeian M, Entezari A, Wang RZ. 2020 Solar powered atmospheric water harvesting with enhanced $\mathrm{LiCl} / \mathrm{MgSO} 4 / \mathrm{ACF}$ composite. Appl Therm Eng 176:115396.

https://doi.org/10.1016/j.applthermaleng.2020.1 15396.

[5] Tu R, Hwang Y. 2020 Reviews of atmospheric water harvesting technologies. Energy 201:117630. https://doi.org/10.1016/j.energy.2020.117630.

[6] Sultan M, El-Sharkawy II, Miyazaki T, Saha BB, Koyama S, Maruyama T, et al. 2016 Water vapor sorption kinetics of polymer based 
sorbents: Theory and experiments. Appl Therm

Eng 106:192-202.

[7] Salehi AA, Ghannadi-Maragheh M, Torab-

Mostaedi M, Torkaman R, Asadollahzadeh M. 2020 A review on the water-energy nexus for drinking water production from humid air. Renew Sustain Energy Rev 120:109627. https://doi.org/10.1016/j.rser.2019.109627.

[8] Sultan M, El-Sharkawy II, Miyazaki T, Saha BB, Koyama S. 2014 Experimental study on carbon based adsorbents for greenhouse dehumidification. Evergr Jt J Nov Carbon Resour Sci Green Asia Strat 1.

[9] Carley KM, Kamneva NY, Reminga J. 2004 Response Surface Methodology: CASOS Technical Report. Network 2:n/a-n/a. https://doi.org/10.1002/wics.73.

[10] Gunst RF, Myers RH, Montgomery DC. 1996 Response Surface Methodology: Process and Product Optimization Using Designed Experiments. Technometrics 38:285. https://doi.org/10.2307/1270613.

[11] Models H. Response Surface Regression. Response n.d.:1-20.

[12] Joshi S, Sherali HD, Tew JD. 1998 An enhanced response surface methodology (RSM) algorithm using gradient deflection and secondorder search strategies. Comput Oper Res 25:531-41.

[13] Kim YJ, Cho BR. 2002 Development of priority-based robust design. Qual Eng 14:35563.

[14] Sultan M, Miyazaki T, Koyama S. 2018 Optimization of adsorption isotherm types for desiccant air-conditioning applications. Renew Energy 121:441-50. https://doi.org/10.1016/j.renene.2018.01.045.

[15] Sultan M, Miyazaki T, Koyama S, Khan ZM. 2018 Performance evaluation of hydrophilic organic polymer sorbents for desiccant airconditioning applications. Adsorpt Sci Technol 36:311-26. https://doi.org/10.1177/0263617417692338.

[16] Ashraf MN, Mahmood MH, Sultan M, Banaeian N, Usman M, Ibrahim SM, et al. 2020 Investigation of Input and Output Energy for Wheat Production: A Comprehensive Study for Tehsil Mailsi ( Pakistan ).

[17] Mahmood MH, Sultan M, Miyazaki T. 2020 Solid desiccant dehumidification-based airconditioning system for agricultural storage application: Theory and experiments. Proc Inst Mech Eng Part A J Power Energy 234:534-47. https://doi.org/10.1177/0957650919869503.

[18] Mekonnen MM, Hoekstra AY, Beysens D, Milimouk I, Nikolayev VS, Muselli M, et al. 2019 Atmospheric water generator. Atmos Res 2:e1500323.

https://doi.org/10.1142/S2010132519500111.

[19] Hanikel N, Prévot MS, Yaghi OM. 2020 MOF water harvesters. Nat Nanotechnol 15:348-55. https://doi.org/10.1038/s41565-020-0673-X.
[20] Talaat MA, Awad MM, Zeidan EB, Hamed AM. 2018 Solar-powered portable apparatus for extracting water from air using desiccant solution. Renew Energy 119:662-74. https://doi.org/10.1016/j.renene.2017.12.050.

[21] Sultan M, El-Sharkawy II, Miyazaki T, Saha BB, Koyama S. 2015 An overview of solid desiccant dehumidification and air conditioning systems. Renew Sustain Energy Rev 46:16-29. https://doi.org/10.1016/j.rser.2015.02.038.

[22] Myers RH, Montgomery DC, Anderson-Cook CM. 2016 Response surface methodology: process and product optimization using designed experiments. John Wiley \& Sons; .

[23] Hamada M, Wu J. 2000 Experiments: planning, analysis, and parameter design optimization.

Wiley New York; .

[24] Khuri AI, Mukhopadhyay S. 2006 GLM designs: the dependence on unknown parameters dilemma. Response Surf. Methodol. Relat. Top., World Scientific;, p. 203-23.

[25] Abdelbasit KM, Plackett RL. 1983 Experimental design for binary data. J Am Stat Assoc 78:90-8.

[26] Hill WJ, Hunter WG. 1966 A review of response surface methodology: a literature survey. Technometrics 8:571-90.

[27] Myers RH, Montgonery D. 2002 DC process and product optimization using designed experiments. New York Montgomery Wiley.

[28] Wu F-C. 2004 Optimization of correlated multiple quality characteristics using desirability function. Qual Eng 17:119-26.

[29] Bradley N. 2007 The response surface methodology.

[30] Ko J, Takata N, Thu K, Miyazaki T. 2019

Dynamic Simulation of a Thermal Management System Consisting of a CO_2 Heat Pump and a Water-Loop.

[31] Liyana-Pathirana C, Shahidi F. 2005 Optimization of extraction of phenolic compounds from wheat using response surface methodology. Food Chem 93:47-56.

[32] Sangsefidi Y, Mehraein M, Ghodsian M, Motalebizadeh MR. 2017 Evaluation and analysis of flow over arced weirs using traditional and response surface methodologies. J Hydraul Eng 143:4017048.

[33] Myers RH, Khuri AI, Vining G. 1992 Response surface alternatives to the Taguchi robust parameter design approach. Am Stat 46:131-9.

[34] Fardous J, Saifuddin AHM, Amena S, Sultana S. 2019 Feasibility study of theophylline solution in water and sodium carboxymethylcellulose.

[35] Hetzner H, Schmid C, Tremmel S, Durst K, Wartzack S. 2014 Empirical-statistical study on the relationship between deposition parameters, process variables, deposition rate and mechanical properties of a-C:H: W coatings. Coatings 4:772-95. https://doi.org/10.3390/coatings4040772. 